\title{
AOR
}

Selected Papers of \#AoIR2019:

The $20^{\text {th }}$ Annual Conference of the Association of Internet Researchers Brisbane, Australia / 2-5 October 2019

\section{OBSERVING THE TECH, USING MEETUP DATA TO STUDY THE EVOLUTION OF IOT}

\author{
Rossi Luca, \\ IT University of Copenhagen \\ Matteo Magnani, \\ Uppsala University \\ Davide Vega D'aurelio \\ Uppsala University \\ Obaida Hanteer, \\ IT University of Copenhagen
}

\section{MeetUp and the loT space}

The study of the relation between online groups and offline relationships has a long and fruitful tradition and highlighted the complex dynamic that takes place in the formation of communities and in the emergence of "alloy" social capital (Xie 2008). While it is certainly possible to claim that all social networking applications and social media could be used to support offline meeting and interactions, the specific class of Event-Based Social Networks has been developed with this specific goal. (Liu, X. et al. 2012). EventBased Social networks (EBSNs) allow users to propose social gatherings and to share and related information. Usually EBSNs also enable users to create groups that will, more or less regularly organize similar events (Ricken, Barkhuus, Jones 2017). Beyond facilitating the practical organization of events EBSN allow the discovery of a critical mass of likeminded individuals often in geographical proximity. Among the existing EBSNs, MeetUp is probably the most famous. MeetUp exists in multiple countries and currently counts more than 323.000 groups and over 39 million members (MeetUp 2018).

While MeetUp has received less research than other OSNs, there are several studies that have focus on the organizational and relational issues (Ricken, Barkhuus, Jones 2017), have tried to measure and predict the future success of MeetUp groups 
(Pramanik et al. 2016), as well as the relation between online and offline interactions (Sessions 2010). This paper proposes to use MeetUp data to study the emergence and the evolution of the technological trend commonly known as Internet of Things (IOT). IoT has sparked a wide enthusiasm worldwide and it has often been described as a revolution that is affecting every aspect of our lives from wearable technologies to smart cities (Valerio 2015). Due to this wide range of envisioned applications the discourse about loT often moved away from the more technical aspects to touch upon topics such as legal frameworks, financial costs and, more recently, ethical and privacy concerns (Lee, Choi \& Kim 2017). While it is undeniable that loT has generated a lot of enthusiasm, it should also be acknowledged over the years we have seen multiple definition of what is actually an loT technology spanning from "intelligent objects" to "global network infrastructure" and "interaction of information" (Lee, Choi \& Kim 2017). Grounding our research on the data describing a qualitatively selected set of loT-related European MeetUp groups, this paper will answer the question: How has the loT space evolved over the years?

\section{Data}

The focus of the project is the European loT. To start mapping the space a part of the research team has inspected all the MeetUp groups found searching for loT (and related keywords) and filtering the results for European groups. If the groups matched the expected criteria they were added to our dataset. This resulted in 220 MeetUp groups. Using the MeetUp APIs, for each group in the dataset several information were retrieved (geographical location, list of members, self-provided description of their topics of interest, and creation date). Additionally, for each event created by the groups, we gathered additional information (expected number of participants, venues, date) as well as for each member of the groups (name, topics of interest and geographical location). The final dataset consists of 220 groups, 32967 members and 2386 events from 2011 until now (Jan 2019).

\section{Results}

In this final section we will briefly introduce the results of the analysis that will be further developed in the final paper. 

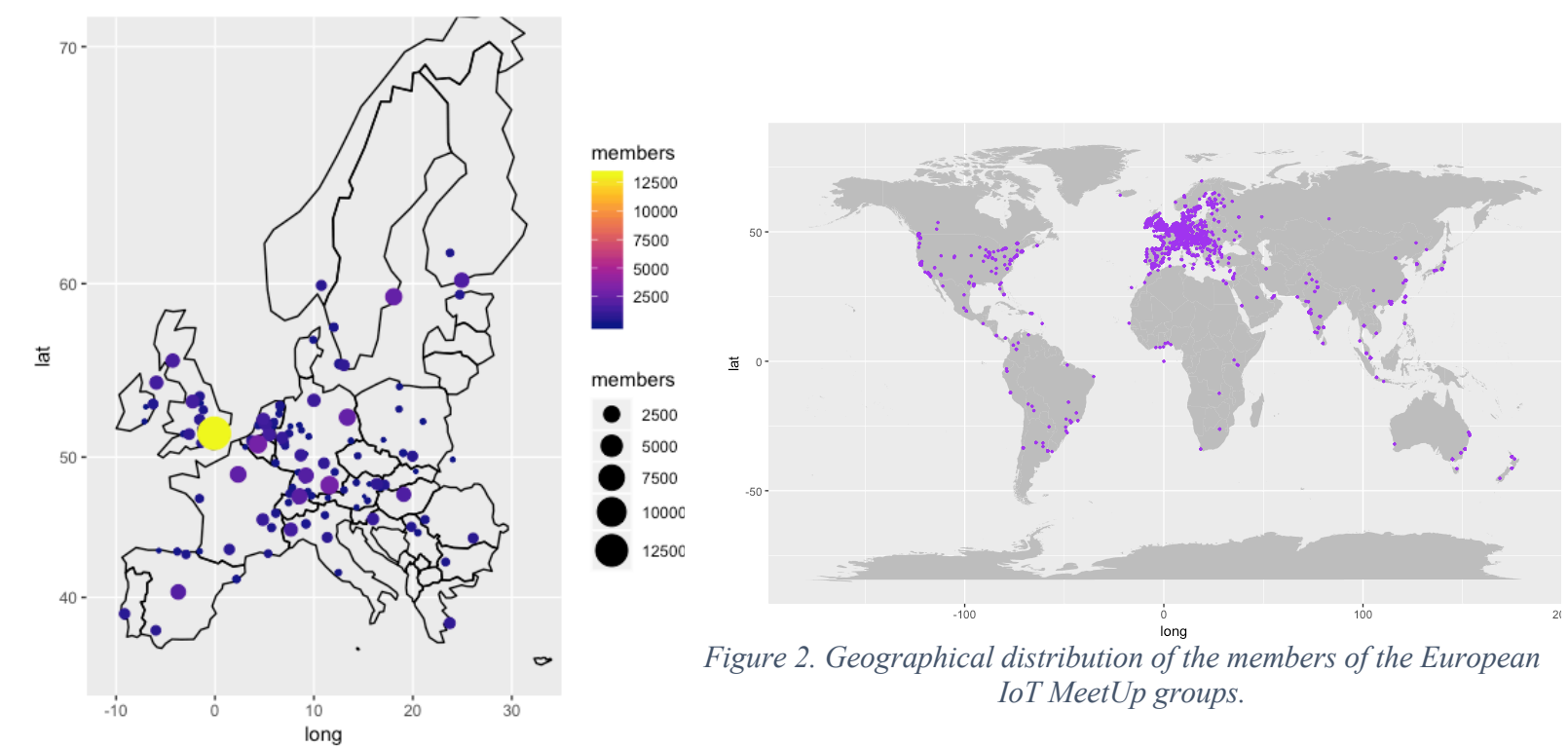

Figure 1. Geographical distribution of IoT groups in

Europe (size represent the number of members)

The geographical information associated with the MeetUp data allows us to visualize the geography of loT-related groups in Europe (Figure 1) and well as the geographical distribution of the members (Figure 2). While Figure 1 allows us to estimate the size of the various national loT scenes and to identify London as the most important hub,

Figure 2 shows an interesting dynamic. The members of the European loT groups selflocate themselves all over the world. This suggests that users might join MeetUp groups because of a temporally limited interest (maybe there were temporally based in Europe for work) and remain members of these groups even when the initial condition disappears.

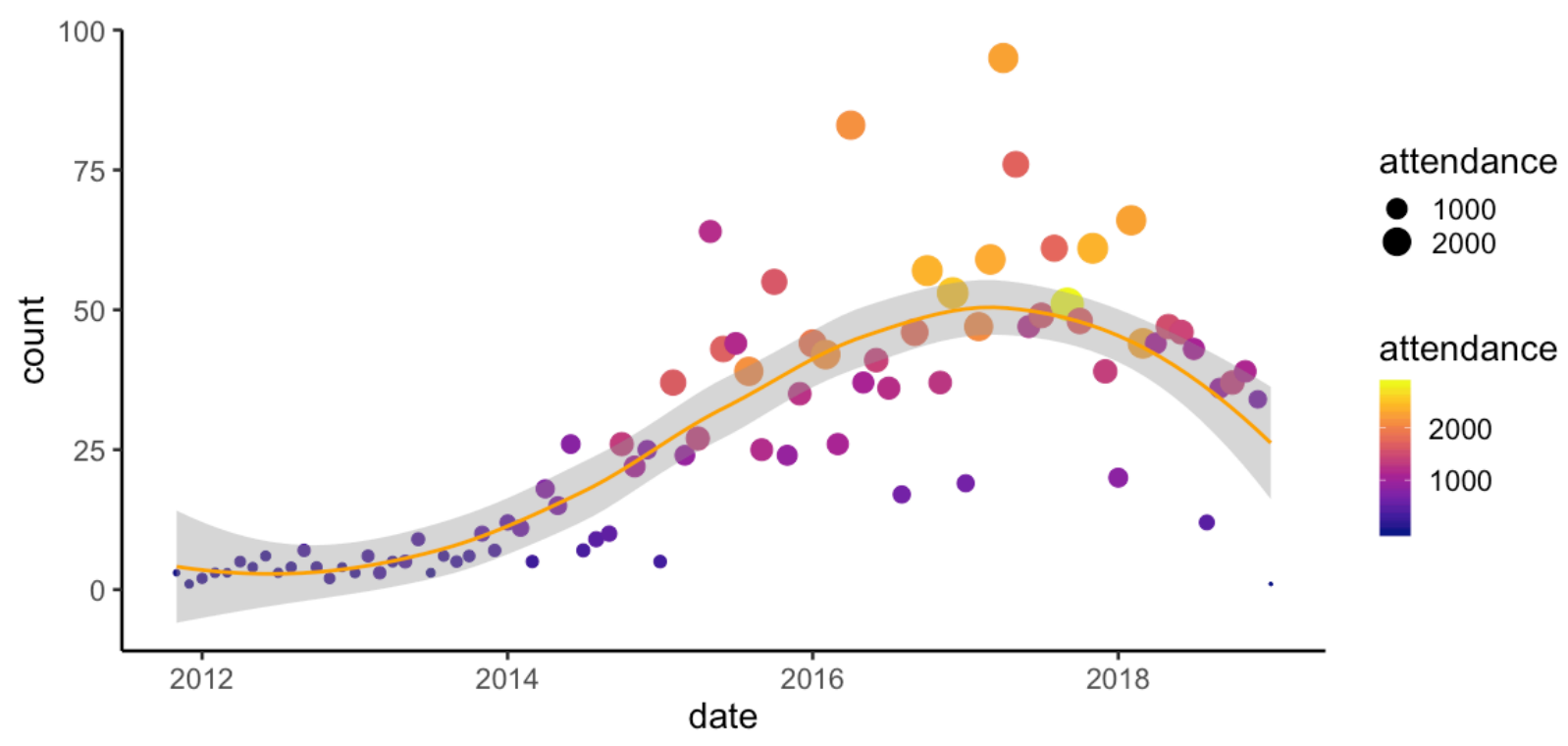

Figure 3. Monthly number and (expected) attendance of IoT events in Europe 
MeetUp data allows also a longitudinal exploration of the European loT scene. Figure 3 shows the temporal evolution of the loT event since 2011. Until 2014 events were relatively few (less than 20 per month) and were expected to attract few people. This dramatically changes after 2015 when we see the emergence of many big events. It should be noted that even if the visualization seems to suggest a decline in the number of events this could be due to the presence of partial incomplete data for 2019.

Another aspect that can be explored is the thematic evolution of the loT space. Thanks to the topics of interests listed by the loT-related groups when they are created,we can visualize the evolution of "proximal" topics of interest. Figure 4 shows how specific keywords emerged strongly during recent years (e.g. Cryptocurrency) while others that were present in the early years have largely disappeared (e.g. Arduino). It should be noted that in order to make Figure 4 readable have been reported only the keywords that were used by at least 5 groups created that year.

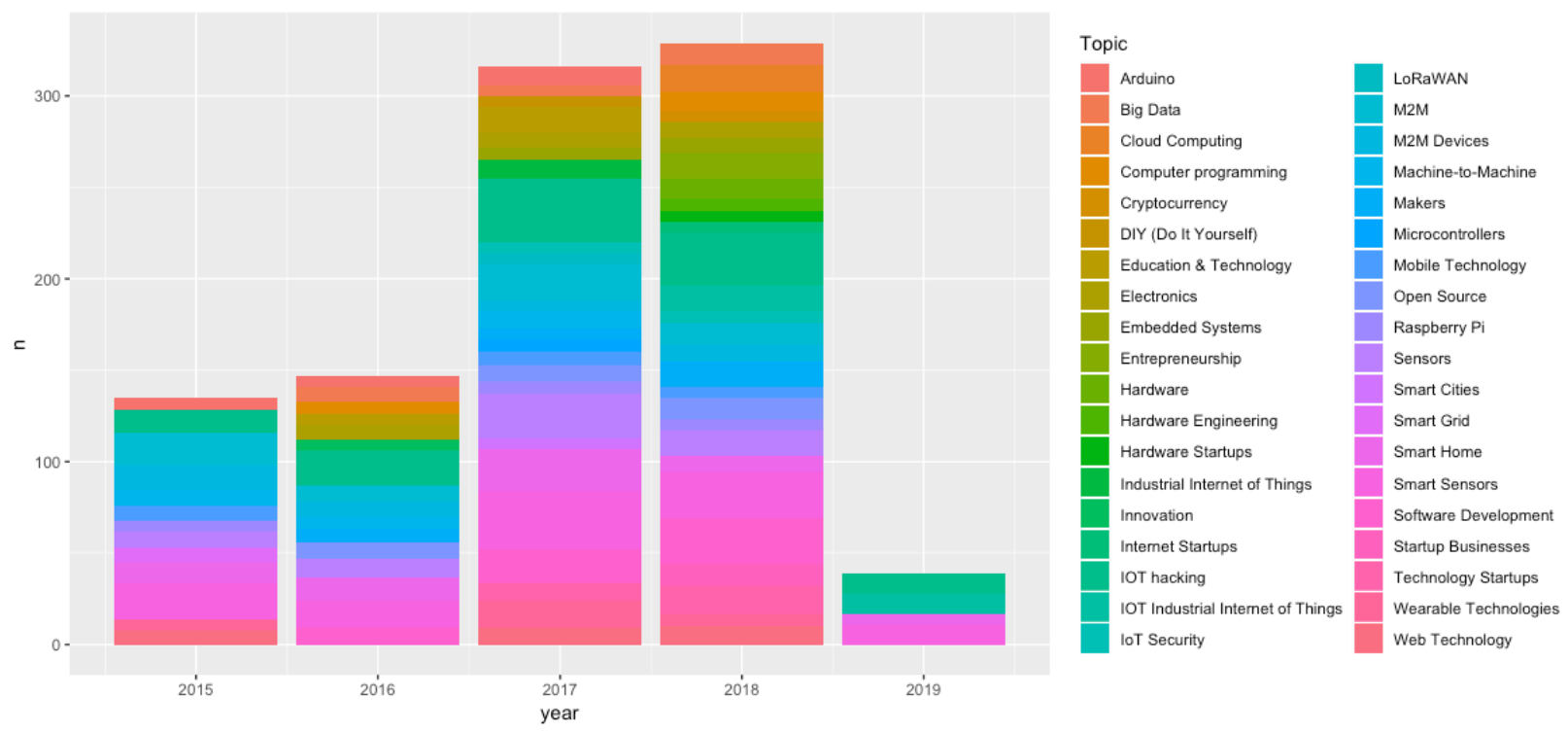

Figure 4. Keyword used to describe the related interests of IoT groups over the years

The presented visualizations offer a glimpse of the possible analysis that can be done on the longitudinal evolution of the loT space using MeetUp data. The preliminary results, that will be detailed in the final presentation, suggest the presence of clearly identifiable European hubs for loT development but a worldwide crowd of users. From a temporal perspective the MeetUp data shows how loT exploded in 2015 and how it might have peaked in 2017. Within this period of time loT has not been a "stable technology" but as evolved incorporating, within its area of "related topics" new and emerging technologies such as Cryptocurrency or cloud computing.

\section{References}


Liu, X. et al. (2012). Event-based social networks: linking the online and offline social worlds. Proceedings of the 18th ACM SIGKDD international conference on Knowledgediscovery and data mining (2012), 1032-1040.

Mok, K. Y., Shen, G. Q., \& Yang, J. (2015). Stakeholder management studies in mega construction projects: A review and future directions. International Journal of Project Management, 33(2), 446-457.

Pramanik, S., Gundapuneni, M., Pathak, S., \& Mitra, B. (2016, March). Predicting group success in meetup. In Tenth International AAAI Conference on Web and Social Media.

Ricken, S., Barkhuus, L., \& Jones, Q. (2017, June). Going online to meet offline: Organizational practices of social activities through meetup. In Proceedings of the 8th International Conference on Communities and Technologies (pp. 139-148). ACM.

Sessions, L. F. (2010). How offline gatherings affect online communities: when virtual community members 'meetup'. Information, Communication \& Society, 13(3), 375-395.

Valerio, P. (2016). Is the lot a tech bubble for cities?: With more cities joining the smart city revolution and investing in sensors and other iot devices, the risk of a new tech bubble is rising. IEEE Consumer Electronics Magazine, 5(1), 61-62.

Xie, B. (2008). The mutual shaping of online and offline social relationships. Information Research, 1(3) 